\title{
Serials
}

\section{Transforming Access to Research Literature for Developing Countries}

\author{
Barbara Kirsop and Leslie Chan
}

Available online 27 October 2005

The economic development of a country depends heavily on its scientific strength and ability to resolve problems in such areas as public health, infectious disease, environmental management, or industrial progress. Access to research information traditionally depends on ability to pay, which has a negative impact on developing countries. A number of new initiatives address this imbalance, ranging from consortial licensing and new publishing models to the Open Access Initiative, and have the ability to meet the needs of research in financially constrained countries. The advent of the Open Access strategies, particularly interoperable institutional archives, has the potential to revolutionize access to essential research. Serials Review 2005; 31:246-255.

(c) 2005 Elsevier Inc. All rights reserved.

The research base of a country has a profound effect on its economic development and its ability to address problems in such areas as public health, infectious diseases, agriculture, environmental management, or industrial progress. ${ }^{1}$ But the way in which research findings are traditionally distributed depends on ability to pay, with the consequence that researchers in developing countries ${ }^{2}$ have very limited access to the academic information they need. In 2003, a study by the World Health Organization (WHO) found that of the seventy-five countries with a GNP per capita per year of less than US\$1,000, 56 percent of medical institutions had no subscriptions to journals over the previous five years, and of countries with GNP between US\$1 and 3,000, 34 percent had no subscriptions to journals, and a further 34 percent had an average of two subscriptions per year. ${ }^{3}$ This is clearly an unacceptable situation, not only to research organizations in the developing world but also to the overall progress of science.

This imbalance was an inevitable consequence of the way in which research has been published and distributed

Kirsop is with the Electronic Publishing Trust for Development, Wilmots, Elmton, Worksop, Nottinghamshire, UK; e-mail: ept@biostrat.demon.co.uk.

Chan is in the Department of Social Sciences, University of Toronto at Scarborough, Toronto, Ontario, Canada; e-mail: chan@utsc.utoronto.ca. in the past, with the publishing industry providing what is now a tried and tested mechanism leading from the research funders, through the authors, referees, publishers, printers, and distributors to the end readers. The cost of this process has been met by the consumers and, over the years, the publishing industry has provided a reliable service. However, the cost of purchasing journals has risen inexorably and it is now a well-recorded fact that more and more academic organizations find themselves disenfranchised.

As libraries have struggled to meet the needs of their colleagues, researchers themselves have become dissatisfied that their libraries can no longer afford to buy back their research output and that of their co-workers, even though this was provided free of cost to the publishers. Similarly, organizations that fund the research have become concerned that the published results of their funding are largely unread and that scientific progress is retarded through inadequate access to related research conducted globally. Until a few years ago, an escape from this anomalous situation was hard to envisage. However, the advent of the Internet and the World Wide Web opened up opportunities that the academic world was not slow to embrace. The ability to distribute research through publications electronically on the Internet offered a means to break the cycle of knowledge starvation and a growing number of initiatives have emerged to test this new opportunity. 
At the same time, academic researchers began to recognize that the global knowledge pool was incomplete since research carried out by regions of the world where 80 percent of the world's population lived was "missing" largely due to the unaffordable costs of printing and distributing local journals. So it is that not only are those working in the developing world unable to afford the publications they need, but their own research output remains largely unknown and unacknowledged.

The ability to access the corpus of the world's research output through the Internet and also to contribute to it on an equal basis has become a tantalizing goal that would benefit all scientists, especially in fields where a global picture is essential for the development of effective international programs (e.g., for infectious disease control and monitoring, for environmental conservation and climate change, for specialized disciplines such as high energy physics or taxonomy).

This article outlines initiatives underway designed to enfranchise the world's research readers while retaining the quality standards required for dissemination of professional articles. Our focus is primarily on access to the primary peer-reviewed literature produced in both the North and the South. The authors compare the likely impact of different access programs on developing country science. While it is clear that the benefits from these initiatives will have the greatest impact on the poorest countries, it is a widely accepted consequence that all academic life will be immeasurably enriched from the widest possible access to publicly funded research output.

\section{New Initiatives, Different Solutions}

Providing free access or lower rates to developing countries is not a new phenomenon. In the past many journals, particularly those published by scholarly or scientific societies, have offered discretionary discounts to subscribers or libraries from developing countries. New and recent initiatives expand the scale, stakeholders, and the process by which journals in electronic format are being offered to developing countries.

These initiatives, some discussed briefly below, are largely based on models of consortial purchasing, national site licensing, and donors' subsidies. They often involve access to packaged journals rather than individual titles. In these developments, the qualifying criteria may vary between initiatives so it is often difficult to know who qualifies and how access is gained. In addition, publishers may change their access policies without much warning, leaving users confused and libraries facing difficulties in collection management. A case in point is the British Medical Journal (http:// www.bmj.com). Long known for its pioneering role in providing free access to its full content since 1999, the journal decided in January 2005 to restrict some of the content to paid subscribers only, while providing free access to research papers to the poorer countries. It is important, therefore, to remember that this review provides only a snapshot in time, and readers are advised to check the Web sites of publishers or initiatives to obtain up-to-date information.

\section{Consortial Licensing Approach: eIFL, PERI}

Consortia purchasing by libraries, which aims to facilitate access to research publications through collective negotiation, has been in place in Europe and North America for some time. The consortial movement became widespread in the mid-1990s, partly in response to the spiraling cost of serials subscriptions, but also to the emergence of new business models made possible by digital technology. However, library consortia in developing countries are still in their infancy, although increasing numbers of regional consortia are being formed in many transitional and developing countries. For example, the Zimbabwe University Libraries Consortium (ZULC) is a grouping of University Libraries in Zimbabwe (http://www. uz.ac.zw/library/zulc/ [Note: no link when last checked on August 30,2005, but available previously]) that has been formed for the purpose of resource sharing, collection development, and related services. ${ }^{4}$ Consortia arrangements have received some criticism from libraries because they often lock purchasers into longterm agreements that cannot be adjusted to meet changed circumstances. Further, some of the commercial packages may not reflect institutional needs and libraries are purchasing packaged journals for which there is no academic requirement.

\section{The Electronic Information for Libraries}

The Electronic Information for Libraries (eIFL), an independent Soros initiative established in 1999, strives to mediate in this process by negotiating, supporting, and advocating for the wide availability of electronic resources by library users in transition and developing countries. Its main focus is on negotiating affordable subscriptions on a multi-country consortial basis, while supporting the enhancement of emerging national library consortia in member countries. As well as negotiating on behalf of libraries, eIFL provides consultancy, training, and general support.

Recognizing the importance of Open Access (OA) to primary research findings for developing countries, eIFL initiated the eIFL-OA program in January 2005 in order to build capacity and raise awareness of OA, as well as to ensure that local content is widely distributed (http:// www.eifl.net). To support the above activities, eIFL conducted a series of OA workshops in partnership with library consortia in South Africa, Ukraine, Lithuania, and in China. ${ }^{5}$ These activities will be further discussed in the later section on Open Access.

\section{INASP-PERI}

One of the well-established initiatives of access to worldwide research is the Programme for the Enhancement of Research Information (PERI; http://www. inasp.info/peri/), coordinated by the International Network for the Availability of Scientific Publications (INASP), an organization established by the International Council for Science (ICSU) in 1992 to improve access to research and dissemination in developing countries. The main objective of PERI is to "support 
capacity building in the research sector in developing and transitional countries by strengthening the production, access and dissemination of information and knowledge" (PERI homepage).

Like eIFL.net, PERI also acts as a negotiator with commercial publishers and information aggregators on behalf of developing countries by securing deeply discounted prices for access to online journals and databases. In addition to playing a key role in reducing cost barriers, INASP has also been instrumental in designing programs that assist local journals with improving their visibility as well as editorial and scientific quality.

The African Journal Online (AJOL) initiative operated by INASP was designed to increase the visibility of African journals by making their abstracts globally available through the INASP Web site and delivering full-text material on request, free to participating countries and at cost to others. To further increase the participation and capacity building of partnering journals, the development and management of the AJOL project was transferred to the National Inquiry Services Centre in South Africa (NISC; http:// www.nisc.co.za/) in early 2005. The AJOL model may be duplicated in countries such as Nepal and Bangladesh in the future. ${ }^{6}$

\section{Differential Licenses: HINARI and AGORA}

\section{HINARI}

One of the best-known journal access initiatives is the Health InterNetwork Access to Research Initiative (HINARI; http://www.healthinternetwork.org/), launched in 2002, and managed by WHO. The program provides free or highly discounted subscription access to major journals in biomedical and related social sciences to non-profit and educational institutions in developing countries. A prior survey by WHO indicated that demand for health information in developing countries is intense, given the grave consequences from inaccessible potential life-saving knowledge. ${ }^{7}$

In the first phase, HINARI consisted of 1,500 journal titles published by six major publishers. By 2004 the number of journals grew to 2,800 , with over sixty publishers. It is noteworthy that publishers participate in the program on a voluntary basis and no formal contract with HINARI has been signed. The program is guaranteed through 2006 and further agreement will likely be developed, though details are not yet available.

In terms of eligibility, institutions in countries with a GNP/capita of US $\$ 1,000$ or less are eligible for free access to HINARI, while countries with a GNP/capita of US\$1,000-3,000 pay an annual fee of $\$ 1,000$ per institution. Institutions that wish to participate in the program need to submit an application to HINARI. By 2004, 1,400 institutions in 104 countries have registered with HINARI. ${ }^{8}$ Ethiopia, Nepal, Sudan, and Vietnam, which are all eligible for free access, have some of the highest number of registered institutions. Each registered institution is given a password to HINARI by WHO staff and individuals belonging to the eligible institutions obtain the password from their librarian (or equivalent). Access is restricted to institutional libraries only. The HINARI portal allows users to access and download full-text articles from participating publishers, search PubMed database through the National Library of Medicine in the United States, and search by subject.

\section{AGORA}

Global Online Research in Agriculture (AGORA; http:// www.aginternetwork.org/) is administered by the United Nations Food and Agriculture Organization (FAO) and is a sister program to HINARI. The aim of AGORA is to improve food and nutritional security by providing free or low cost access to over 400 scientific journals in agriculture and related sciences to public institutions in developing countries.

Launched in October 2003 and using the same eligibility criteria based on GNP, 440 institutions from fifty-six countries (of sixty-nine eligible) had registered for AGORA in 2004. AGORA operates on the same access and portal approach as HINARI and "trains the trainer" on the use of electronic resources. As in the case of HINARI, users are required to register with FAO and access is password controlled. Individual publishers reserve the right to add to or delete from the list of journals they offer so the number of journals in the database is an estimate only.

\section{Access through Institutions in the North: Ptolemy and eJDS}

\section{Ptolemy}

Ptolemy (http://www.ptolemy.ca) is a unique model for electronic access to medical literature for doctors in developing countries, created by surgeons and doctors working at the University of Toronto. Currently, the project gives 150 East African physicians access to the University of Toronto Library online journal collection by making the physicians "research affiliates" of the Office of International Surgery. Under the publishers' licensing terms, these users have access to the full-text resources of the university library via a secure Internet system that monitors and verifies usage. Users also become part of the study about research needs, literature citation patterns, and subsequent impact on users' clinical, research, and teaching practices.

Unlike large-scale projects such as HINARI, which limits usage to the library and whose users are not well defined, the Ptolemy project engages with a well-defined group of end users in an electronic research community and provides them with direct access from their own home or offices, where Internet connectivity may be better than in the user's workplace institutions. It is the hope that the project will contribute directly to building research capacity in Africa. Given the small scale, the project also has the potential for being widely reproduced, so that other institutions in the North could identify and "adopt" or "twin" with other research communities in the South who are in need of access. 


\section{eJournals Delivery Service}

eJournals Delivery Service (eJDS), the free eJournals Delivery Service (http://www.ejds.org), is a new initiative of the Abdus Salam International Centre for Theoretical Physics, Trieste, Italy. The project applies open source information technologies to allow developing world scientists to search and download selected scientific articles using e-mail only and/or via Web/e-mail gateways. The project is made possible through agreements with several key scientific publishers and societies who provide the e-contents free. Only mathematics and physics publications are available through the service and only users from developing countries who apply to the program are eligible. Users are also subject to a download limitation. The eJDS team believes that this delivery model could be expanded to other disciplines beyond physics. Usage data for the program are not yet available.

\section{Open Access Initiatives}

While the initiatives described above have been largely dependent on publishers, the academic community has been considering alternative mechanisms that could meet scientific needs and access to journal publications for the development of global research. At a landmark meeting initiated by the Open Society Institute (OSI) in Budapest in 2001, experts met to discuss future directions. The proposals made at this meeting, now known as the Budapest Open Access Initiative (BOAI), have had a profound effect on the development of Open Access initiatives worldwide.

The guiding principle of the Open Access movement to scientific literature is the conviction that scientific and technical information is a quintessential global public good that should be freely available for the benefit of all. The current system of scientific publishing is contrary to this ethos because some commercial publishers are placing excessive price and permission barriers on publications of research that is largely supported by public funds. Effectively, the public goods have been turned into a high price commodity affordable only to those who have the financial resources.

The differential pricing schemes described above mask the fundamental issue that publicly funded research should be accessible to the public without further barriers. The "free" access to online journals given to the poorest of the poor countries is not true Open Access, as the cost is subsidized by sponsoring agencies, donors, and other subscribers.

In the past two years, government bodies and large research funding agencies in the developed world have begun to recognize the inefficiency of a system where results of publicly funded research are widely unavailable for future research development. The plethora of declarations following the BOAI, such as the Berlin Declaration, ${ }^{10}$ the Bethesda Statement on Open Access, ${ }^{11}$ and IFLA's statement $^{12}$ are now well-known examples of international calls for Open Access to publicly funded research.

There are two broad and complementary strategies for providing Open Access to scientific research. One is through Open Access Archiving (OAA) of published research material and the other is through the development of OA journals (OA Publishing or OAP) in which the costs of publication are not met by the readers but by other means, such as the authors' institute or funding bodies.

These two complementary strategies have now been widely endorsed or recommended by major international organizations such as CERN, Wellcome Trust, and Research Councils UK. National OA policies are also now in place in Scotland, Finland, Netherlands, and elsewhere. A list of policies has been compiled in the Electronic Publishing Trust for Development Web site (http://www.epublishingtrust.org/openaccess.htm).

\section{Open Access Publishing (OAP)}

OA journal publishing, and in particular the input-pay model where the author's institute pays for the publication cost per article, is being pioneered by such organizations as BioMedCentral (http://www.biomedcentral. com) and the Public Library of Science (http://www.plos. org). Not surprisingly, there is a great deal of ongoing and often heated debate about the economic viability of this model, particularly for authors from developing countries. Even though publishing fees for authors from developing countries are currently waived by these two publishers if requested, the long-term sustainability of this approach is not clear.

While the input-pay model is an important development, other OAP initiatives have emerged with different funding models, particularly initiatives designed in developing countries for local and regional scientific and health needs that also serve the global scientific community.

\section{SciELO}

One of the pioneers of OA journal publishing in developing countries is the Scientific Electronic Library Online (SciELO; http://www.scielo.br) project from Brazil. Through SciELO, readers worldwide can access 125 journals in health and other sciences published in Brazil and other Latin American countries. A collaboration between the Foundation for the Support of Science of Sao Paulo (FAPESP) and the Latin America and Caribbean Center on Health Sciences Information BIREME (http://www.bireme.org), SciELO demonstrates how significant government funding and support can dramatically improve the global visibility, accessibility, and impact of science from Brazil and other regions of Latin America, ${ }^{13}$ while at the same time bridging the South to South knowledge gap. ${ }^{14}$

In addition, BIREME developed an index to journals from Latin America and the Caribbean known as LILACS (http://lilacs.bvsalud.org) to further improve the visibility of journals from these regions. In collaboration with the Pan American Health Organization (PAHO) and a number of other agencies, BIREME also developed the Virtual Health Library (http://www.bvsalud.org) that provides free online access to a range of health journals that are highly relevant to health workers in the region. This collab- 
orative approach is seen as the way forward for providing "health information for all by 2015."15

In September 2005, BIREME, the Pan American Health Organization, and WHO are hosting a parallel open access meeting at the 9th World Congress on Health Information and Libraries in Salvador, Bahia, Brazil. ${ }^{16}$ Important issues about open access in general will be debated, as will specific issues facing OA journal publishing in developing countries, such as funding and long-term sustainability, integration with other electronic health resources, and re-use of scientific information, as well as collaborative and partnership models.

A common approach to OA publishing is to provide the online version of the journal articles free, while maintaining print subscriptions. An increasing number of journals from developing countries are practicing this approach.

\section{IndMed}

While important initiatives are taking place in Latin America, parallel initiatives are taking place in India. The India MEDLARS Centre, National Informatics Centre, New Delhi, India, has developed a full-text database of thirty-five free biomedical journals published in India (http://indmed.nic.in) and the number of journals in the database is growing steadily.

Medknow Publications, a fast-growing publisher based in Mumbai, is a leading OA journal publisher in India, providing publication services and open access to twenty medical journals in India.

The Indian Academy of Sciences, based in Bangalore, publishes eleven journals and they are all freely accessible on the Web (http://www.ias.ac.in/). The Indian National Science Academy, based in New Delhi, has also made available several of its publication free online (http://www.insa.ac.in/html/home.asp).

\section{Open Access Aggregator: Bioline International}

Bioline International (BI), an open access aggregator of journals from developing countries, is a case study of the tangible benefits and impacts of Open Access and is described in depth. Since 1993, Bioline International (http://www.bioline.org.br) has provided free online hosting services to publishers who do not have the resources or technical infrastructure to provide online access to their journals. ${ }^{17} \mathrm{BI}$ is a unique North-South partnership with the University of Toronto, the Centro de Referência em Informação Ambiental (CRIA) in Brazil, and the Electronic Publishing Trust for Development, a charitable organization based in the UK, as well as participating publishers from various developing countries.

There are now over forty journals on the Bioline system, with publications from several African countries, as well as from India, Brazil, Colombia, Cuba, Chile, Turkey, and Venezuela. The subject coverage of these journals is mainly in the health and biological sciences. All the journals are published by non-profit scholarly societies or university departments. Most of the journals' operating costs are heavily dependent on subsidies by aid and funding agencies, society dues, and, in a small number of cases, author page charges. The journals join Bioline with the goal of increasing the usage and impact of their publications through open access.

Bioline International employs open source software to minimize cost and to maximize exposure of metadata, as well as full text of the participating journals. The BI platform consists of two key servers: the primary server resides in CRIA in Brazil (http://www.bioline.org.br), while an Eprints server (http://bioline.utsc.utoronto.ca), which mirrors the content of the primary server and stores the files in PDF format, resides at the University of Toronto in Canada. The two servers are cross-linked to maximize exposure of the metadata to multiple search services and directories.

Since February 2005, the BI primary server is also available through the Open Archive Initiative Protocol for Metadata Harvesting (OAI-PMH) as an OAI Data Provider. This was achieved by writing specific Perl scripts that are able to understand requests directed to http://www.bioline.org.br/oai, in accordance with the OAI-PMH version 2.0. Becoming OAI compliant was a major milestone because the material stored is not only available through the main Bioline Web site but also can be harvested by any other OAI Service Provider existing throughout the Internet.

To further maximize content, BI is registered with Oaister.org, an OAI Service Provider that harvests a large number of institutional repositories from around the world. The journals on the BI system are listed on the Directory of Open Access Journals (http://www. doaj.org), which also provides metadata for libraries that wish to link directly to the BI journals. Many of the African-based journals on the BI system are also indexed and cross-listed in the African Journal Online project (http://www.ajol.org), further increasing the visibility of the content.

Commercial service providers are also beginning to take note of BI, and EBSCO's A-Z service has been listing BI material since 2003. Since April 2004, the BI Eprints server has been indexed by ISI Current Web Content, and in March 2005, Ulrich's Periodicals Directory $^{\mathrm{TM}}$ also began listing BI contents. These services promise to improve the visibility of the contents and also integrate the contents of regional journals into the mainstream databases.

While hits and downloads of Web documents are at best a rough estimate of usage, they are, nonetheless, a good indicator for change in usage pattern over time. Total hits for the Bioline Eprints server increased from 43,441 in September 2003 to 437,150 in April 2005, while the total number of hits in the year 2004 amounted to $2,014,790$, with an average of 167,899 hits per month. The total files downloaded increased from 30,374 in September 2003 to 372,258 in April 2005. The total number of files downloaded in the year 2004 was $1,218,030$ with an average of 95,462 files downloaded per month.

For the primary Bioline server, the total number of hits was 114,821 in September 2003 and rose to 966,753 in April 2005. The total hits for the year 2004 was $3,490,191$, with an average of 276,129 per 
month. Total files downloaded rose from 107,970 in September 2003 to 885,312 in April 2005. Total files downloaded for the year 2004 was $3,387,812$, with an average of 282,317 downloads per month.

Table 1 shows the number of articles downloaded from the ten most visited journals on Bioline. The increase in usage over time is markedly clear.

In addition to data from server logs, there are other important quality indicators that point to the potential impact of Open Access. The Journal of Postgraduate Medicine (JPGM), published by the Staff Society of GS Medical College and KEM Hospital in Mumbai, India, has in particular documented significant developments in terms of author submissions and the country of origins of contributing authors. ${ }^{18}$

The total number of submissions to JPGM increased from 190 in 2000 to 629 in 2004. The number of submissions from authors outside India has risen from less than 10 percent in 2001 to 38 percent (166) in 2003 and 30 percent (189) in 2004. This is an indication that authors from outside India increasingly see JPGM as an "international" journal capable of reaching a global audience (data from D.K. Sahu).

An important consequence of the growing visibility and accessibility of JPGM is the increasing citation of its articles, as illustrated in Table 2.

The data presented here suggest that usage of publications on the BI platform has increased steadily over the past few years and that increased awareness and accessibility of the journals, at least in the case of JPGM, are translated into improved quality of the journals through higher numbers of submissions, submissions from international authors, and increased citation rates. Although the Impact Factor of JPGM is still very low relative to other mainstream journals indexed in ISI, what is of note is the steady increase in the number over the past few years. What remains to be seen is whether this phenomenon is spreading to the other journals on the system, and BI is working closely with the various publishing partners to track the necessary data.

What is particularly encouraging is that citation analysis, once dominated by ISI's Journal Citation Report and its Impact Factor, is now giving way to other forms of Web-based citation linking and impact analysis made possible by open access to the primary research publications. The high referral rates to BI contents by Google and Yahoo indicate that most users are accessing the BI material through the common free search engines rather than through the dedicated OAIster search service or fee-based services. The new Google Scholar service has the potential to provide even more promising citation linking information for Open Access quality scientific and academic materials, further enhancing the value of OA. ${ }^{19}$

\section{Open Access Archives (OAA)}

Despite the importance of OA publishing for small journals from developing countries, the total number of journal articles published by regional journals is outnumbered by the total number of articles developing country scientists choose to publish in "international journals." As these journals are generally not available locally due to price barriers, much of the published research by developing country scientists still remains invisible to local scientists.

Equally significant, the total number of journals listed in DOAJ (1,677 as at the time of writing this paper) constitutes only about 7 percent of the world's 23,000 peer-reviewed titles listed by Ulrich (http:// www.ulrichsweb.com/ulrichsweb/), which means much of the peer-reviewed literature is still unavailable through OA publishing. For this reason, some advocates of Open Access believe that the fastest and most efficient way of building up local and international research capacity is for each institution to build its own digital repository to house and make available the intellectual output of their faculty and affiliates. ${ }^{20}$

The establishment of OA Archives (often called institutional repositories if developed by institutions such as universities, or subject-based repositories if developed by a discipline or community of interest) may contain much important scholarly output (theses, conference proceedings, etc.), but the authors consider here the deposit of refereed journal articles. According to the SHERPA/ROMEO study of publisher's policy on author self-archiving, 90 percent of publishers surveyed allow authors to deposit their publications into their institutional repositories. ${ }^{21}$

Table 1. The ten journals with the highest number of articles and their respective hits from 2002 to 2004

\begin{tabular}{lrrr}
\hline \multicolumn{1}{c}{ Journal Name } & \multicolumn{1}{c}{ Year } \\
\cline { 2 - 4 } & \multicolumn{1}{c}{2002} & \multicolumn{1}{c}{2003} & 2004 \\
\hline Memórias do Instituto Oswaldo Cruz (2,068 articles) & 11,526 & 33,001 & 116,971 \\
Neurology India (583 articles) & 0 & 13,295 & 41,836 \\
Journal of Postgraduate Medicine (500 articles) & 2,635 & 28,187 & 43,392 \\
African Crop Science Journal (368 articles) & 6,319 & 18,556 & 37,716 \\
Agricultura Técnica (263 articles) & 856 & 9,946 & 27,621 \\
Indian Journal of Dermatology, Venereology and Leprology (253 articles) & 0 & 1,489 & 14,997 \\
Indian Journal of Surgery (237 articles) & 0 & 11,256 & 38,389 \\
African Journal of Biotechnology (212 articles) & 249 & 11,948 & 45,732 \\
Electronic Journal of Biotechnology (203 articles) & 0 & 9,169 & 37,502 \\
Indian Journal of Medical Sciences (157 articles) & 0 & 7,894 & 46,358 \\
\hline
\end{tabular}


Table 2. Figures showing the increasing impact factor of JPGM, data from D.K. Sahu (sources: ISI Web of Science, Scopus, Google Scholar)

\begin{tabular}{ccccc}
$\begin{array}{c}\text { Publication } \\
\text { year }\end{array}$ & $\begin{array}{c}\text { Citation } \\
\text { year }\end{array}$ & $\begin{array}{c}\text { Total number of } \\
\text { citations in scientific } \\
\text { journals (A) }\end{array}$ & $\begin{array}{c}\text { No. of articles other } \\
\text { than editorials, letters, } \\
\text { and news (B) }\end{array}$ & $\begin{array}{c}\text { Impact factor } \\
\text { A/B }\end{array}$ \\
\hline $1998-1999$ & 2000 & 2 & 111 & 0.03 \\
$1999-2000$ & 2001 & 12 & 147 & 0.11 \\
$2000-2001$ & 2002 & 34 & 155 & 0.23 \\
$2001-2002$ & 2003 & 62 & 173 & 0.40 \\
$2002-2003$ & 2004 & 137 & 0.78 \\
\hline
\end{tabular}

The development of OA Archives has been somewhat hampered by widespread misunderstandings between OA, OA Publishing and OA Archiving. Clarification is becoming widely communicated and the number of institutional archives that have been set up is now growing steadily. A Registry of OA Archives has been established (http://archives.eprints.org/eprints.php) and 466 archives had been registered by August 2005. This is double the number that existed eight months ago, and a number of archives exist that have not yet been registered. The number of articles in the archives must now reach hundreds of thousands, representing a very large body of research publications available free to all. In addition to the registry there is a list of university policies on OA, which is beginning to be filled (http://www.eprints.org/ signup/fulllist.php) and can provide guidelines for other universities.

Most archives are institutional, but some centralized archives have been established that are based on discipline. The best known of these is arXive (http:// arxive.org) that has existed for over a decade and is a major resource for the high energy physics community. There is debate as to whether centralized or distributed archives offer the best solution. Since all such archives are interoperable, the precise location of the host archive is immaterial to the end user who can search all archives seamlessly; however, there are substantial additional benefits from institutional archives. As well as using them as a measure of their research output, they can serve as tools for assessment exercises, for promotion and grant applications, and since material other than published papers may be archived and separately tagged, as a general administrative tool. For developing countries, such archives showcase their research output and provide greatly increased visibility. The number of archives set up in developing countries is fifty-four, and as awareness-raising exercises and workshops reach more scientific communities around the world, the benefits are increasingly recognized.

The following centralized Open Access Archives are already operating:

PubMedCentral is a digital archive of life sciences journal literature maintained at the U.S. National Institutes of Health (NIH), developed and managed by NIH's National Center for Biotechnology Information (NCBI) in the National Library of Medicine (NLM). The time lag between publication and archiving has been the subject of strong debate and is determined by the policy applying to the publication being deposited. However, NIH is currently requiring that its own funded research be archived within one year of publication. This period is considered unacceptable by much of the academic community, particularly for fast-moving sciences where access to the latest research results is critical. This change represents a backward step from the NIH's original intention to archive soon after publication and at the latest within six months of publication. Nevertheless, the corpus of archived material from this resource represents a big improvement on availability of published research for developing countries, while remaining a disappointing outcome for those concerned with the development of research.

PubMedCentral UK is a new initiative announced by a group of British scientific bodies. On May 12, 2005, the group said they were seeking proposals from organizations interested in running a new freeaccess archive of papers arising from research they have funded. The idea is to establish a UK version of the U.S. National Institutes of Health PubMed Central. The site would include material from the United States as well as from the UK and would create a searchable facility containing all papers from both versions. UK PubMed Central would also have links to online resources, such as gene and chemical compound databases. The archive is being developed by the Wellcome Trust, the Medical Research Council (MRC), the Biotechnology and Biological Sciences Research Council, the British Heart Foundation, and the Arthritis Research Campaign, with support from the Joint Information Systems Committee (JISC). The time between publication and archiving is not yet established, but it is hoped that it will not extend beyond six months.

The far greater number of institutional (non-centralized) archives now set up are listed in the registry mentioned above. The countries and research organizations now adopting the OA strategy are listed in the Electronic Publishing Trust for Development Web site (http://www.epublishingtrust.org/openaccess.htm). A more extended source of information on the progress of OA is the SPARC Open Access Forum (SOAF), edited 
by Peter Suber (http://www.earlham.edu/ peters/fos/). This includes a monthly newsletter, as well as a timeline of OA development, lists, conferences, and open access discussions.

\section{Impact of Initiatives on Science in Developing and Emerging Countries}

\section{Benefits from Publishers' Initiatives}

The mixture of services available, licensing terms, and eligibility criteria can cause confusion and often disappointment to librarians and users in the developing world. It can be disappointing when cost barriers are imposed for some services and then not applied to others, or when the country of the user does not qualify for free access due to a publisher's marketing policy. Some offers have closed. When this happens, there is no archive of literature available for future use and little capacity has been built so that ultimately users are no further forward than before the program was introduced. As publishers are free to change their policies if they wish, this does not lead to a stable environment for scientific development.

While programs such as HINARI and AGORA have undoubtedly helped fill the knowledge gap, they are clearly not an ideal solution to closing the universal information shortage and are unlikely ever to do so. Commercial collaborators in these programs will always need to consider commercial needs and trim their sails accordingly. Without technology transfer and capacity building these initiatives will serve more as timely sticking plaster solutions than permanent answers. As well as the instability of the strategies, the technology is not always geared to low bandwidth users and many users reporting on the Health Information Forum network (HIF-net), while valuing the information available, have only been able to use the services successfully when they had access to higher speed communications, such as at British Council offices or major institutes. Although the number of journals available through these programs is now of some size, the volume on offer will never meet the full academic requirements of research organizations in the poorer countries.

\section{Benefits from OA Publishing Initiatives}

The development of new journals that are completely free of charge to the readers clearly meets the needs of the scientific community more fully than any subsidized programs. Not only are the journals aiming to address the real research needs of the world, but also the publishers are committed to future sustainability of the material. Further, these new economic models are taking advantage of advanced technology to include valuable links to scientific databases (such as sequence, protein, or taxonomic databases) and are able to provide faster peer review procedures leading to faster publications. It is inevitably slow to build up trust in new journals and the organizations are frustrated at the slow progress. However, recent statistics show a very high impact factor for PloS Biology, ${ }^{22}$ which should boost confidence for potential authors and speed progress for similar initia- tives. Although there remains substantial lack of awareness and much promotion must still be carried out, it would seem that from the point of view of poorer countries, free access to a growing corpus of high quality reviewed material is a very positive development.

There is a downside to the benefits for developing country science. As has been said, the costs of document processing must be met by authors or their institutes. The costs per paper can be very high $(\$ 3,000$ for publishing in the PloS journals, \$500 for publishing in BioMedCentral). For developing countries such costs are prohibitive. Recognizing this, BMC, for example, offers to waive the costs, but authors or their institutes must apply for this dispensation and prove they qualify. This process is a disincentive for authors from poorer nations to publish in these journals. Although all articles are free to all to read, the system is less than perfect for authors from developing countries wishing to publish in them. Interestingly, however, in India there are now seventy-five OA journals, all published by scholarly societies or universities and none charging document management fees (Subbiah Arunachalam, August 2005, personal communication).

Bioline International does not fit into this category since it is not a publisher but a distributor of journals published in developing countries. As such, the publishers meet the publishing costs themselves (and still provide and sell print versions if they wish to do so and have a market for sales) and conversion of digitally received material to OA-compatible format is free of charge. The material received from publishers comes in steadily improved formats as the publishers learn new conversion technologies. So the Bioline service builds capacity, makes no charge for formatting and is free to all readers. More important, as earlier discussion indicated, once the authors recognize that by publishing in an OA journal the impact of their work is greatly increased, it is no longer a disadvantage to publish in their local journals. This, in time, will boost local publishing and lead to a more stable collaborative research environment.

\section{Benefits from OA Archives}

The primary goal of Open Access is to improve the visibility and subsequent impact of research publications. The research impact of archived documents is far greater than with cost-restricted material (in the range of 300-500 percent), ${ }^{23}$ and it is hardly a surprising finding that end users will use what is freely and easily available to them in preference to material that imposes financial barriers.

Given the availability of open source software for building OA Archives and the low technical barriers, setting up an archive is relatively easy. However, while most publishers have given the "green" light for authors to self-archive, take-up rate has been slow across institutions. The exceptions to this are institutions such as the University of Southampton, where there is a clear policy from university administration that requires faculty or researchers to deposit their papers into an institutional archive. A recent JISC study by Alma Swan and Sheridan Brown ${ }^{24}$ showed that the major cause of low archiving rates was a lack of awareness of OA. When faculty was 
asked if they would archive their publications if this were required by their authorities, 84 percent were willing to do so. Some respondents felt that archiving would become a burden, but a further study showed that the time taken for archiving a paper was reduced from about thirty minutes for the first paper to just a few minutes once the procedure had become familiar.

Recent policy statements in support of Open Access archiving, such as that announced in June 2005 by the eight UK Research Councils (http://www.rcuk.ac.uk/ access/cover.asp), will provide a major boost to development and indeed in most cases will require deposit of outputs from their funded research in OA archives. The Wellcome Trust has already instituted a policy requiring Trust-funded research to be either published in an OA journal or be deposited in a central repository, such as PubMedCentral. It is likely that over the next year many funding agencies and government bodies in developed countries will propose similar requirements, and the progress of OA will be much accelerated.

As progress is made in the developed countries, policy makers and senior administrators in the developing world need to be made aware that OA Archives promote and advance the visibility and impact of research from disadvantaged regions, leading to partnerships and ensuring the inclusion of the 'missing' research in the establishment of appropriate international programs. Currently, major advocacy programs are underway which will lead to a growing library of research publications, accessible by all.

\section{Next Steps}

The Internet provides many opportunities for scholarly exchange, and this article presents a number of initiatives already started. For the scientific environment to be stable, sustainable, and secure, judgments must be made as to which strategy best meets these criteria for the future of international science. This judgment is particularly important for funding agencies, which need to assess proposals as to the best value for money and must always be aware of trading short-term gains for long-term stability.

As the dust from the Open Access revolution begins to settle and the concept becomes widely accepted as the way ahead for scientific information exchange in the future, the establishment of OA Archives emerges as a faster, cheaper, and simpler route to reach the ultimate goal of universal Open Access. Not only is it a policy that, through multiple interoperable OA archives and mirror sites, can provide the essential permanence of research information, but also it is a "can do" policy. The costs and workload can be shared, as with all distributed bottomup systems. Its low cost-low maintenance character means it is entirely appropriate for adoption by poorer countries, as is already being shown. Importantly, academic communities can have confidence in the archiving strategy since little else changes in existing publishing practices. Publishers continue to publish and market their products as at present; authors continue to publish in their preferred journals; peer-review continues; and libraries still purchase as their budgets and needs allow. All that is required to achieve the benefits of Open Access is for authors to take one further step and deposit a copy of their final refereed publications in an OA Archive.

Many Open Access workshops have now been held in developing and transitional countries, focusing primarily on setting up OA Archives. The eIFL program has supported a number of these (in 2004/5 in Ukraine, South Africa, India, China, etc.) and others are planned. Other funding organizations, such as the British Council and incountry institutes (such as the Indian Academy of Science and MS Swaminathan Research Foundation), are supporting such initiatives, recognizing the importance of greatly increased access to essential research and the incorporation of their own research into the international arena.

The United Nations, World Heath Organization, and other international agencies need to recognize that current spending on subsidies can be better diverted to such a low-cost sustainable measure. In parallel, OA publishing will certainly make progress as funding, impact statistics, and confidence grow.

Acceptance of Open Access is the most fundamental strategy for the progress of scientific exchange, which will lay the groundwork for future innovations. With time, new ideas about the future of 'the journal' will be formulated. Ideas already exist about the integration of the traditional research report with the primary data and many scholars envisage big changes in the direction to which research "publications" will move in the future. ${ }^{25}$ These innovations can become a reality with the continuing development of the Internet, with fast-moving changes in search procedures and database integration. The priority, however, is to get essential research information out to all research organizations, regardless of their ability to pay. A united global development could lead to a monumental impact on scientific progress in all regions of the world and, in turn, lead to major improvements in health and the control of infectious diseases, in agriculture and monitoring the environment, and so to the relief of poverty.

\section{Notes}

1. UNESCO, Draft medium-term plan (1984-1989). Second part, VII (pp. 135-143), Information systems and access to knowledge. General conference fourth extraordinary session, Paris (1982), Paris, UNESCO (http://unesdoc.unesco.org/images/0005/ 000507/050794eo.pdf); OECD, National innovation systems (1997) Paris, OECD.

2. The term developing country has always been difficult to define because of its inherent connotation that the industrialized state enjoyed by rich countries is what other countries are striving towards. The World Bank's definition of developing countries based on a country's Gross National Product (GNP) is also overly simplistic as it overlooks the highly heterogeneous sociopolitical, cultural, and economic diversity within and between developing countries. Because of the inherent problems with defining developing countries, the terms low-income countries and The South are also used in this paper as a short hand to refer to the poorer, less technologically advanced nations of the world, as opposed to 'The North,' which includes the richer, industrialized states. These are also common terms used to describe the disparities in information and knowledge flow. 
3. Barbara Aronson, "Improving Online Access to Medical Information for Low-Income Countries," New England Journal of Medicine 350, no. 10 (2004): 966-968.

4. Other examples of consortia are China Academic Library and Information System (CALIS); Estonian Library Network Consortium (ELNET); and Lebanese Academic Library Consortium (LALC).

5. Details of these workshops are available at http://www.eifl.net/ services/activities.html (accessed August 30, 2005).

6. See Pippa Smart, "Two-Way Traffic: Information Exchange Between the Developing and Developed World," Serials 17, no. 2 (2004): 184-187; Nyerhovwo J. Tonukari, "Research Communications in the 21st Century," African Journal of Biotechnology 3, no. 2 (2004): 123-126.

7. Aronson, "Improving Online Access."

8. Mary Ochs, Barbara Aronson and Jane Wu, "HINARI and AGORA: Revolutionizing Access to Scientific Information in the Developing World," Serials 17, no. 2 (2004): 175-182.

9. Massey Beveridge, Andrew Howard, Kisteen Burton and Warren Holder, "The Ptolemy Project: A Scalable Model for Delivering Health Information in Africa," British Medical Journal 327 (October 4, 2003): 790-793.

10. See http://www.zim.mpg.de/openaccess-berlin/berlindeclaration. html (accessed August 30, 2005).

11. See http://www.wellcome.ac.uk/en/1/awtvispolpub.html (accessed August 30, 2005).

12. See http://www.ifla.org/V/cdoc/open-access04.html (accessed August 30, 2005).

13. José Rodrigues Coura and Licane de C.B. Willcox, "Impact Factor, Scientific Production, and Quality of Brazilian Medical Journals," Memórias do Instituto Oswaldo Cruz 98, no. 3 (2003): 293-297.

14. Abel Packer, "Scielo-A Model for Cooperative Electronic Publishing in Developing Countries," D-Lib Magazine 6, no. 10 (2000); Carlos Henriqué Macondes and Luis Fernando Sayão, "The Scielo Brazilian Scientific Gateway and Open Archive," D-Lib Magazine 9, no. 3 (2003) (www.dlib.org/march03/ marcondes/03marcondes.html).

15. Fiona Godlee, Neil Pakenham-Walsh, Dan Ncayiyana, Barbara Cohen and Abel Packer, "Can We Achieve Health Information for all by 2015?," Lancet (2004): (published online July 9, 2004).

16. See http://www.icml9.org/meetings/openaccess/ (accessed August 30, 2005).

17. Vanderlei Canhos, Leslie Chan and Barbara Kirsop, "Bioline Publications: How Its Evolution Has Mirrored the Growth of the Internet," Learned Publishing 14, no. 1 (2001): 41-48.
18. Sandeep Bavdekar and Dr. Karshik Sahu, "Path of Progress: Report of an Eventful Year," Journal of Postgraduate Medicine 51, no. 1 (2005): 5-8.

19. Martin Myhill, "Google Scholar," Charleston Advisor 6, no. 4 (2005) (www.charlestonco.com/review/cfm?id=225).

20. Steven Harnad, "The Self-Archiving Initiative," Nature 410 (2001): 1024-1025; also "Open Access to Peer-Reviewed Research through Author/Institution Self-Archiving: Maximizing Research Impact by Maximizing Online Access," in Digital Libraries: Policy Planning and Practice, Judith Andrews and Derek Law (United Kingdom: Ashgate Publishing, 2004); Leslie Chan, Barbara Kirsop, "Open Archiving Opportunities for Developing Countries: Towards Equitable Distribution of Global Knowledge", Ariadne 30 (2001); Steven Harnad, Tim Brody, "Comparing the Impact of Open Access (OA) vs. Non-OA Articles in the Same Journals," DLib Magazine 10, no. 6 (2004); Steven Harnad, Tim Brody, Francois Vallières, Less Carr, Steve Hitchcock, Yves Gingras, Charles Oppenheim, Heinrich Stammerjohanns and Enerhardt Hilf, "The Access/Impact Problem and the Green and Gold Roads to Open Access," Serials Review 30, no. 4 (2004): 310-314.

21. See http://www.sherpa.ac.uk/romeo.php (accessed August 30, 2005).

22. See http://www.plos.org/news/announce_pbioif.html (accessed August 30, 2005).

23. Steve Lawrence, "Online or Invisible," Nature 411, no. 6837 (2001): 521; Tim Brody, Heinrich Stammerjohanns, Steven Harnad, Yves Gingras and Charles Oppenheim, "The Effect of Open Access on Citation Impact," National Policies on Open Access (OA) Provision for University Research Output: An International Meeting, February 19, 2004, Southampton, 2004; Tim Brody, Steven Harnad, and Les Carr, "Earlier Web Usage Statistics as Predictors of Later Citation Impact," Journal of the American Society for Information Science and Technology, in press.

24. Alma Swan and Sheridan Brown, "Open Access Self-archivingAn Author Study," (2005), http://eprints.ecs.soton.ac.uk/10999/ (accessed August 30, 2005).

25. John Houghton, Colin Steele, and Margaret Henty, "Changing Research Practices in the Digital Information and Communication Environment," Department of Education, Science and Training, Australia, August 2002 (2003), www.cfses.com/ documents/Changing_Research_Practices.pdf; Herbert Van de Sompel, Sandy Payette, John Erickson, Carl Lagoze, Simeon Warner, "Rethinking Scholarly Communication: Building the System that Scholars Deserve," D-Lib Magazine 10 (2004); Simeon Warner, "The Transformation of Scholarly Communication," Learned Publishing 18 (2005): 177-185. 